\title{
Assessment of vascular reactivity in rat brain glioma by measuring regional blood volume during graded hypoxic hypoxia
}

\author{
C Julien ${ }^{*, 1}$, J-F Payen ',2, I Troprès', R Farion', E Grillon', O Montigon' and C Rémy' \\ 'Unité Mixte INSERM/UJF 594, LRC CEA 30 V, Pavillon B, BP 217, Hôpital Albert Michallon, F-38043 Grenoble, France; ²Département d'Anesthésie- \\ Réanimation, Hôpital Albert Michallon, F-38043 Grenoble, France
}

While morphological and molecular events during angiogenesis in brain glioma have been extensively studied, the functional properties of tumour vessels have yet received little attention. We have determined changes in regional blood volume (BV) during graded hypoxic hypoxia using susceptibility contrast magnetic resonance imaging in a model of rat brain glioma. Nine anaesthetised and ventilated rats with $\mathrm{C} 6$ glioma were subjected to incremental reduction in the fraction of inspired oxygen $\left(\mathrm{FiO}_{2}\right): 0.35,0.25,0.15$, $0.12,0.10$ and reoxygenation to 0.35. At each episode, BV was determined in peritumoral, intratumoral and contralateral regions. Baseline $\mathrm{BV}$ values $\left(\mathrm{FiO}_{2}\right.$ of 0.35$)$ were higher in peritumoral than in the contralateral and intratumoral regions. Progressive hypoxia resulted in a graded increase in $\mathrm{BV}$ in contralateral and peritumoral regions. $\mathrm{At} \mathrm{FiO}_{2}$ of 0.10 , $\mathrm{BV}$ increases were comparable between these two regions: $49 \pm 22 \%$ (s.d.) and $28 \pm 17 \%$ with respect of control values, respectively. These BV changes reversed during the reoxygenation episode. By contrast, the intratumoral region had a significant increase in $\mathrm{BV}$ at $\mathrm{FiO}_{2}$ of 0.10 only, with no evidence of return to the basal value during reoxygenation. Immunohistochemical staining of $\alpha$-smooth muscle actin confirmed reactivity of vessels in the peritumoral region. Our findings indicate that peritumoral vessels present a vascular reactivity to hypoxia, which is comparable to that of nontumoral vessels. A method is thus available for noninvasively demonstrating whether any particular vascular modifying strategy results in the desired outcome in terms of tumour blood volume changes.

British Journal of Cancer (2004) 91, 374-380. doi:10.1038/sj.bjc.6601908 www.bjcancer.com

Published online 8 June 2004

(c) 2004 Cancer Research UK

Keywords: cerebral blood volume; brain; magnetic resonance imaging; tumour; glioma; hypoxia

Mechanisms of brain glioma proliferation have been extensively studied. This tumour grows initially by cooptation of existing host vessels (Holash et al, 1999). In a second phase, the host vessels regress, leading to a secondary avascular tumour and eventually to angiogenesis. The switch to an angiogenic phenotype results from a positive balance between proangiogenic factors, for example, vascular endothelium growth factor (VEGF) and antiangiogenic factors (Folkman and Klagsbrun, 1987). Hypoxia may play a major role in the induction of the angiogenic switch (Shweiki et al, 1992), as hypoxic perinecrotic regions and VEGF expression have been closely related (Damert et al, 1997; Rofstad and Danielsen, 1999). Vascular endothelium growth factor produced in the hypoxic region induces formation of neovessels in the peritumoral region. Three regions can be thus distinguished during advanced development of brain glioma: a central region with necrosis and no vessels; a peritumoral region with a high degree of angiogenesis, including tumour tissue and nontumour tissue at the edge of the tumour and containing tumour cells; and an intermediate region with large, tortuous and pleomorphic vessels (Deane and Lantos, 1981; Zama et al, 1991).

*Correspondence: Dr C Julien, Laboratoire Hypoxie-Physiopathologie, Faculté de Médecine, Domaine de la Merci, F-38700 La Tronche, France; E-mail: cecile.julien@ujf-grenoble.fr

Received 20 October 2003; revised 12 March 2004; accepted 20 April 2004; published online 8 June 2004
Few studies have been aimed at investigating the functional properties of the vessels in brain glioma (Mazurchuk et al, 1999). Yet, the possibility to enhance local blood flow in the tumoral tissue presents interest in view of enhancing drug delivery to the tumoral tissue. One way to explore the cerebrovascular reactivity is to measure blood volume (BV) response to hypoxic hypoxia (low $\mathrm{PaO} 2$ ), which is a potent vasodilator in brain (Kontos et al, 1978). We recently measured regional cerebral BV response to hypoxic hypoxia in normal rats, using susceptibility contrast magnetic resonance imaging (MRI) (Julien-Dolbec et al, 2002). By measuring BV response to hypoxic hypoxia in a model of rat brain glioma, our goal was to assess overall vessel reactivity to hypoxia in those tumours and to determine possible differences in responsiveness between intratumoral, peritumoral and nontumoral areas. We defined peritumoral region as the region at the edge of the tumour having the largest BV due to a high vessel density.

\section{MATERIALS AND METHODS}

\section{Animal preparation}

Animals were prepared in accordance with the guidelines of the French Government (decree No. 87-848 of 19 October 1987, licenses 006683 and A38071) and with the UKCCCR Guidelines for the Welfare of Animals in Experimental Neoplasia (Workman et al, 1998). A total of 26 Wistar female rats 
$(160-180 \mathrm{~g})$ were studied. For the purpose of tumour implantation, rats were anaesthetised with an intraperitoneal injection of chloral hydrate $\left(400 \mathrm{mg} \mathrm{kg}^{-1}\right)$. A cell suspension of C6 glioma $\left(10^{5}\right.$ cells in $5 \mu$ l of a culture medium without foetal calf serum) was stereotaxically injected using a Hamilton syringe through a burr hole $(1 \mathrm{~mm}$ diameter $)$ in the right striatum $(7 \mathrm{~mm}$ anterior to the zero ear bars, $3 \mathrm{~mm}$ right to the midline, $3 \mathrm{~mm}$ depth from the dura). The C6 glioma cell line was established by Benda et al (1971) from a methyl-nitrosourea-induced rat glioma. The C6 cells were cultured in Dulbeco's modified Eagle's medium (DMEM, GilboBRL, Lifes technologies, Scotland) supplemented with $10 \%$ foetal calf serum (GilboBRL, Lifes technologies, Scotland), $50 \mathrm{U} \mathrm{ml}^{-1}$ penicillin and $50 \mu \mathrm{g} \mathrm{ml}^{-1}$ streptomycin.

The MRI study was performed during the 4 th week after tumour implantation, so that significant tumour growth and brain neovessels could be observed (Peoc'h et al, 1999). Anaesthesia was induced with $4 \%$ halothane and then maintained with an intraperitoneal injection of thiopental $\left(20 \mathrm{mg} \mathrm{kg}^{-1}\right)$. In total, $1 \%$ lidocaine was injected subcutaneously for local anaesthesia at all surgical sites. After tracheostomy, rats were mechanically ventilated with $65 \%$ nitrous oxide- $35 \%$ oxygen using a rodent ventilator (Model 683, Harvard Apparatus Inc., South Natick, MA, USA). Ventilation was adjusted to maintain partial arterial $\mathrm{CO}_{2}$ pressure $\left(\mathrm{PaCO}_{2}\right)$ at $\approx 35 \mathrm{mmHg}$. The fraction of inspired oxygen $\left(\mathrm{FiO}_{2}\right)$ was continuously monitored (MiniOX I analyser, Catalyst Research Corporation, Owings Mills, MD, USA). A $0.7-\mathrm{mm}$ indwelling catheter was inserted into the left femoral artery to monitor mean arterial blood pressure (MABP) via a chart recorder (8000S, Gould Electronic, Ballainvilliers, France). Blood gases $\left(\mathrm{PaO}_{2}\right.$ and $\left.\mathrm{PaCO}_{2}\right)$, arterial saturation of haemoglobin in oxygen $\left(\mathrm{SaO}_{2}\right)$, arterial $\mathrm{pH}(\mathrm{pHa})$ and haemoglobin content $(\mathrm{Hb})$ were analysed from less than $0.1 \mathrm{ml}$ arterial blood samples (ABL 510, Radiometer, Copenhagen, Denmark). Another $0.7-\mathrm{mm}$ indwelling catheter was inserted into the left femoral vein to continuously infuse a normal saline solution containing epinephrine $\left(25 \mathrm{ng} \mathrm{min}^{-1}\right)$ and sodium bicarbonate $\left(0.4 \mu \mathrm{molmin}^{-1}\right)$ at a rate of $2 \mathrm{ml} \mathrm{h}^{-1}$ throughout the study. Epinephrine was required to protect from the adverse effects of combined anaesthesia and hypoxic hypoxia on the cardiovascular system. Sodium bicarbonate was used to prevent arterial acidosis. Canulation of the femoral vein was also required for the injection of the contrast agent. Rectal temperature was maintained at $37.5 \pm 0.5^{\circ} \mathrm{C}$ by using a heating pad placed under the abdomen.

\section{Experimental protocol}

Animals were subjected to a stepwise lowered $\mathrm{FiO}_{2}$ : control episode $\left(\mathrm{FiO}_{2}\right.$ of 0.35$)$, normoxia episode $\left(\mathrm{FiO}_{2}\right.$ of 0.25$)$, hypoxic episodes $\left(\mathrm{FiO}_{2}\right.$ of $0.15,0.12$ and 0.10$)$ and reoxygenation episode $\left(\mathrm{FiO}_{2}\right.$ of 0.35) (Figure 1). The basic cycle started after a $30 \mathrm{~min}$ equilibration episode at $\mathrm{FiO}_{2}$ of 0.35 (control). The initial criteria for exclusion from the study were: MABP $<100 \mathrm{mmHg}, \mathrm{pHa}<7.30, \mathrm{PaO}_{2}$ $<100 \mathrm{mmHg}, \mathrm{Hb}<10 \mathrm{~g} \mathrm{dl}^{-1}$. The subsequent episodes were then first induced by lowering the inhaled oxygen for $\mathrm{FiO}_{2}=0.25$, then by replacing the oxygen by air ( $\mathrm{FiO} 2$ of 0.15 and 0.12 ). During these four episodes, fractions of inspired nitrous oxide were 0.65 , $0.75,0.25$ and 0.40 , respectively. Reoxygenation was obtained by restoring the oxygen in the gas mixture. Each $\mathrm{FiO}_{2}$ episode (normoxia, hypoxia and reoxygenation) lasted $10 \mathrm{~min}$ : a $4 \mathrm{~min}$ equilibrium period followed by MRI acquisition and determination of MABP and arterial blood sampling. If MABP $<70 \mathrm{mmHg}, \mathrm{pHa}$ $<7.30$ or $\mathrm{PaCO}_{2}<27 \mathrm{mmHg}$ at $\mathrm{FiO}_{2}$ of $0.25,0.15$ and 0.12 , the animal was excluded from the study. No exclusion criterion was applied at $\mathrm{FiO}_{2}$ of 0.10 (severe hypoxia) and during the reoxygenation episode. When the cycle of measurements ended, rats were killed by administration of an overdose of thiopental $\left(50 \mathrm{mg} \mathrm{kg}^{-1}\right)$. Brains were excised from the skull for histological study, and frozen in isopentane at $-50^{\circ} \mathrm{C}$ and stored at $-80^{\circ} \mathrm{C}$.

\section{Magnetic resonance imaging measurement}

Magnetic resonance imaging was performed with a $2.35 \mathrm{~T}, 40-\mathrm{cm}$ diameter horizontal bore magnet (Bruker Spectrospin, Wissenbourg, France) equipped with a $20-\mathrm{cm}$ diameter actively shielded gradient (Magnex Scientific Ltd, Adingdon, UK) and with a SMIS console (SMIS Ltd, Guildford, UK). The rat was lying prone, its head secured via ear bars. A 30-mm diameter surface coil was located directly above the brain. After radiofrequency coil matching and tuning, the magnetic field homogeneity was adjusted to obtain a linewidth for water smaller than 0.5 part per million in the brain. Six adjacent horizontal slices (from $2 \mathrm{~mm}$ below bregma) were chosen from a coronal $\mathrm{T}_{1}$-weighted image. A series of $\mathrm{T}_{2}{ }^{*}$ weighted images for each slice was acquired at different echo times using a multigradient-echo sequence with an echo spacing interval of $4.2 \mathrm{~ms}$ (repetition time $T_{\mathrm{R}}=2,000 \mathrm{~ms}$; first echo time $T_{\mathrm{E}}=7.6 \mathrm{~ms} ; 64 \times 32$ data acquisition image matrix; number of averages $=2$; field of view $=35 \times 35 \mathrm{~mm}^{2}$; slice thickness $=1 \mathrm{~mm}$; number of slices =6). Acquisition of all images of the six slices took about $3 \mathrm{~min}$.

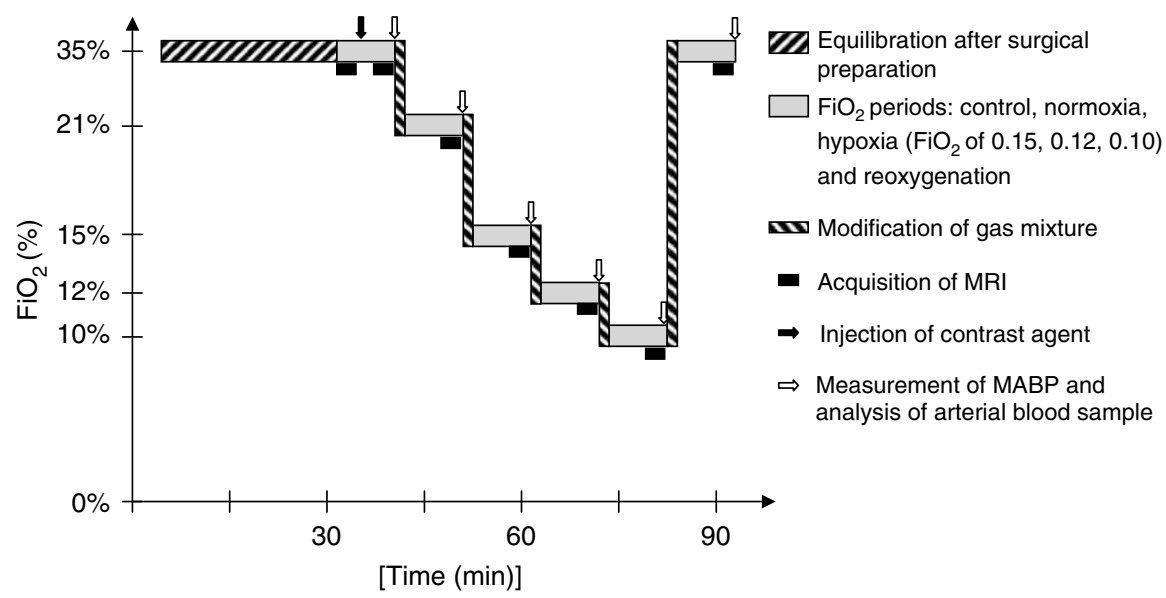

Figure I Experimental protocol for the BV measurements in rat brain tumour during graded hypoxic hypoxia. Magnetic resonance imaging was performed before injection of contrast agent at the beginning of the control episode. Postcontrast MRI, mean arterial blood pressure (MABP) measurement and arterial blood gas analysis were performed 4 min after onset of each $\mathrm{FiO}_{2}$ level. 
A superparamagnetic iron oxide contrast agent was intravenously injected $(200 \mu \mathrm{mol}$ of iron per $\mathrm{kg}$ body mass of AMI-227, Sinerem ${ }^{\mathbb{R}}$; Guerbet, Aulnay-sous-Bois, France) $30 \mathrm{~min}$ after the start of the experiment $\left(\mathrm{FiO}_{2}\right.$ of 0.35$)$. Images were acquired before ( $n=24$ echoes, precontrast image) and $3 \mathrm{~min}$ after injection ( $n=12$ echoes, postcontrast image). Acquisition of postcontrast images was then repeated at the end of each subsequent $\mathrm{FiO}_{2}$ episode $\left(\mathrm{FiO}_{2}\right.$ of $0.25,0.15,0.12$ and 0.10 , and reoxygenation).

\section{Magnetic resonance imaging analysis}

Image processing and determination of $\mathrm{BV}$ were performed using an Ultrasparc workstation (Sun Microsystems, Pasadena, CA, USA). Susceptibility contrast MRI exploits the increase in the magnetic susceptibility difference $(\Delta \chi)$ between the intravascular and the extravascular compartments induced by the presence of a long-lived intravascular contrast agent. This increase in $\Delta \chi$ results in an increase $\Delta R_{2}{ }^{*}$ of the transverse decay rate $\left(R_{2}{ }^{*}=1 / T_{2}{ }^{*}\right)$ of the NMR signal from the water protons. $\Delta R_{2}^{*}$ is proportional to BV as previously shown (Yablonskiy and Haacke, 1994; Boxerman et al, 1995; Tropres et al, 2001):

$$
\mathrm{BV}=\frac{3}{4 \pi} \frac{\Delta R_{2}^{*}}{\gamma \Delta \chi B_{0}}
$$

where $\gamma$ is the gyromagnetic ratio, $\Delta \chi$ the susceptibility difference, $B_{0}$ the magnetic field in the absence of sample. For an injection of AMI-227 of $200 \mu \mathrm{mol}$ of iron per $\mathrm{kg}, \Delta \chi$ was equal to 0.688 part per million at $2.35 \mathrm{~T}$ in large vessels (Tropres et al, 2001). Since measurements were performed in brain microcirculation, $\Delta \chi$ value was corrected by the ratio of haematocrit between brain microcirculation and large vessels that corresponded to 0.83 (Bereczki et al, 1993). This resulted in a $\Delta \chi$ value of 0.571 (Payen et al, 1998). We also assumed that the brain haematocrit remains constant during hypoxic hypoxia, as previously shown in most brain areas (Bereczki et al, 1993). Regional BV is expressed as the

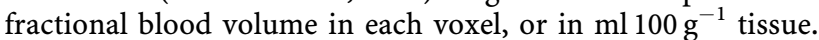

For each $\mathrm{FiO}_{2}$ episode, $T_{2}{ }^{*}$ maps were calculated by a leastsquares monoexponential fit of the signal intensity $v s$ the echo time on a pixel by pixel basis. Differences in relaxation rates in each pixel were then calculated according to the formula:

$$
\Delta R_{2}^{*}=\frac{1}{T_{2 \text { pre }}{ }^{*}}-\frac{1}{T_{2 \text { post }}{ }^{*}}
$$

with $T_{2 \text { pre }}{ }^{*}$ and $T_{2 \text { post }}{ }^{*}$ are the relaxation times before and after administration of the contrast agent, respectively. The $\Delta R_{2}{ }^{*}$ values were measured during the six successive $\mathrm{FiO}_{2}$ episodes. Three regions of interest (ROI) were defined on the $T_{2}{ }^{*}$-weighted images (first echo) acquired at $\mathrm{FiO}_{2}$ of 0.10 (Figure 2): peritumoral region $(\approx 192$ pixels) corresponding to the hyposignal at the edge of the tumour on the $T_{2}{ }^{*}$-weighted images, intratumoral region $(\approx 62$ pixels) corresponding to hypersignal inside the tumour on the $T_{2}{ }^{*}$ weighted images and contralateral (striatum) region ( $\approx 44$ pixels). Pixels with excessive $\Delta R_{2}{ }^{*}$ values $\left(>200 \mathrm{~s}^{-1}\right)$, that is, BV larger than $13.3 \mathrm{ml} .100 \mathrm{~g}^{-1}$, during any $\mathrm{FiO}_{2}$ episode were discarded (Figure $3 \mathrm{~B}$ ). This threshold corresponds to the upper limit of validity of the linear relationship between $\Delta R_{2}{ }^{*}$ and $\mathrm{BV}$. Selection of the ROI was made at $\mathrm{FiO}_{2}$ of 0.10 because it corresponded to the highest number of pixels to be discarded. A correction for clearance of the contrast agent from the plasma (elimination halftime $\approx 4.5 \mathrm{~h}$ ) was applied since the postcontrast experiments lasted $\approx 75 \mathrm{~min}$. This correction has been described elsewhere (Payen et al, 1998).

\section{Histological study}

Two groups of excised brains were sliced in horizontal plane using a cryotome $(10 \mu \mathrm{m}$ thick). The first group included all rat brains studied by MRI. A total of 24 brain sections located in the MRI slice were obtained every $250 \mu \mathrm{m}$. Haematoxylin erythrosin safran (HES) staining was used to characterise the brain tumour (localisation, size and regions). In the second group of excised brains (rats excluded from the MRI study due to the physiological inclusion criteria), three adjacent brain sections were obtained from the largest tumour surface. One of these sections was stained using HES to characterise brain tumour. Another brain section was immunostained using goat anti-collagen primary antibody $(1: 100$; $1 \mathrm{~h}$ at $4{ }^{\circ} \mathrm{C}$ ) (Southern Biotechnology Associates, Birmingham, AL, USA) and biotinylated anti-goat secondary antibody (1:500; $30 \mathrm{~min}$ at room temperature) (Santa Cruz Biotechnology, Santa Cruz, CA, USA) to identify mature and immature brain vessels. The last brain section was immunostained using mouse anti- $\alpha$ smooth muscle actin ( $\alpha$-SMA) primary antibody $(1: 500 ; 1 \mathrm{~h}$ at $4{ }^{\circ}$ ) (Dako, Glostrup, Denmark) and biotinylated anti-mouse secondary antibody $(1: 1000 ; 30 \mathrm{~min}$ at room temperature) (Valbiotech, Paris, France) to identify immature brain vessels. Biotinylated antibodies were detected using extravidin-peroxidase $(1: 1000 ; 30 \mathrm{~min}$ at room temperature) (Sigma-Aldrich, SaintQuentin Fallavier, France). The sections were rinsed three times with phosphate-buffered saline (Sigma-Aldrich, Saint-Quentin Fallavier, France) between incubations. The sections were analysed using an optical microscope at low and high magnification $(\times 100$
A

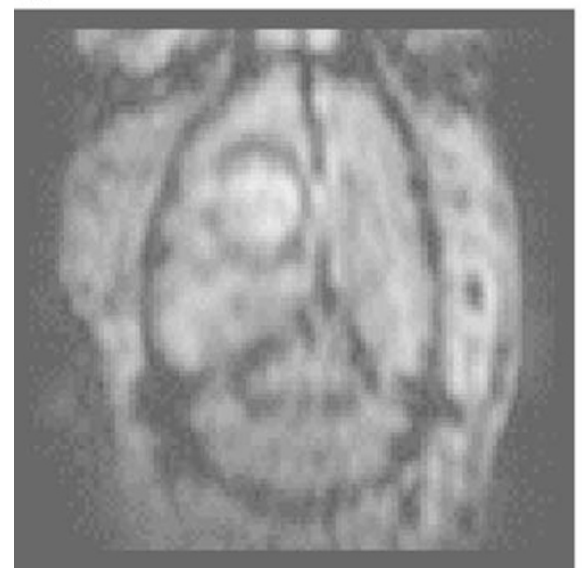

B

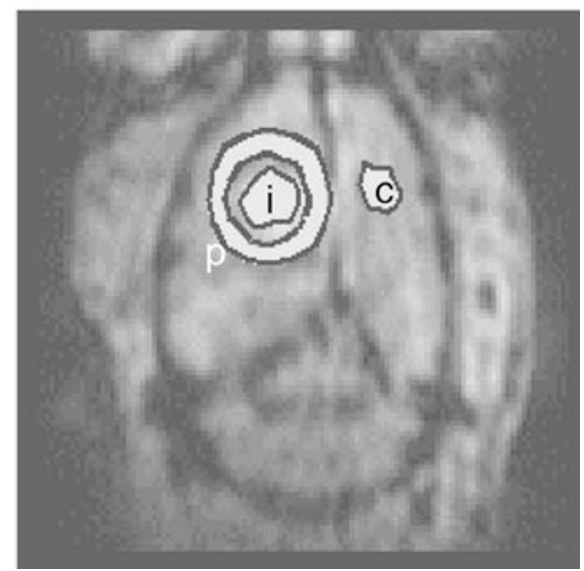

Figure 2 Regions of interest $(\mathrm{ROI})$ defined on $T_{2}{ }^{*}$-weighted images: peritumoral $(\mathrm{p})$, intratumoral (i) and contralateral (c) regions. The $T_{2}{ }^{*}$-weighted images (first echo) acquired at $\mathrm{FiO}_{2}$ of $0.10(\mathbf{A})$ were used to select $\mathrm{ROI}(\mathbf{B})$. 
and $\times 200$ ). Histological analysis was qualitative and allowed verification of brain tumour growth, confirmation of the ROI selection made for MRI analysis, and documentation of tumour vascular architecture.

\section{Statistical analysis}

Data are expressed as mean \pm s.d. Analysis for statistical significance of changes during the successive episodes was performed using one-way analysis of variance (ANOVA) for repeated measurements (StatView SE program, Abacus Concepts Inc., California, USA). To examine regional differences in the response to hypoxia, interaction between brain regions and episodes was assessed using two-way ANOVA $\left(\mathrm{ROI} \times \mathrm{FiO}_{2}\right.$ episodes $)$ for repeated measurements. Each value at a given episode was compared to that obtained at another episode using the Scheffé post hoc test. Difference in $\mathrm{BV}$ between brain regions at each $\mathrm{FiO}_{2}$ episode was tested using a one-way ANOVA for repeated measurements. Peritumoral and intratumoral regions were compared to the contralateral values using the Scheffé post hoc test. Statistical significance threshold was $P=0.05$.

\section{RESULTS}

Of the 26 rats, 17 were excluded from the MRI study for the following reasons: MABP $<100 \mathrm{mmHg}, \mathrm{Hb}<10 \mathrm{~g} \mathrm{dl}^{-1}$ or $\mathrm{pHa}$
$<7.30$ during control episode $(n=5)$; MABP $<70 \mathrm{mmHg}, \mathrm{PaCO}_{2}$ $<27 \mathrm{mmHg}$ or $\mathrm{pHa}<7.30$ during hypoxia episodes $(n=9)$, absence of brain tumour $(n=3)$. Therefore, the cerebrovascular response to graded hypoxic hypoxia was investigated in nine rats with brain glioma.

Physiological data are shown in Table 1. Hypoxic hypoxia caused a significant decrease in MABP and hypocapnia at $\mathrm{FiO}_{2}$ of 0.10. All parameters returned to control value during reoxygenation episode. Changes in $\mathrm{pHa}$ or in $\mathrm{Hb}$ were not observed throughout the study.

Typical $\Delta R_{2}{ }^{*}$ images are shown in Figure 3A. Administration of the contrast agent resulted in decrease of the $T_{2}{ }^{\star}$ values, leading to positive $\Delta R_{2}{ }^{*}$ in the brain. The largest $\Delta R_{2}{ }^{*}$ values (corresponding to high $\mathrm{BV}$ ) were observed in the peritumoral region. The lowest $\Delta R_{2}{ }^{*}$ values were observed in the intratumoral region. Excluded pixels $\left(\mathrm{BV}>13.3 \mathrm{ml} .100 \mathrm{~g}^{-1}\right.$ ) were mainly observed in the peritumoral region at $\mathrm{FiO}_{2}$ of 0.35 (Figure 3B). As $\mathrm{FiO}_{2}$ was decreased, the number of pixels excluded increased, reaching a maximum at $\mathrm{FiO}_{2}$ of 0.10 .

There was a significant interaction between brain regions and $\mathrm{FiO}_{2}$ episodes $(F=5.19 ; P<0.01)$, meaning that a regional difference was found in the response to hypoxia. Interfactor analysis showed that peritumoral BV $\left(3.4 \pm 0.7 \mathrm{ml}_{\left.100 \mathrm{~g}^{-1}\right)}\right.$ was significantly higher than contralateral $\left(2.2 \pm 0.6 \mathrm{ml} .100 \mathrm{~g}^{-1}\right)$ and intratumoral $\left(1.1 \pm 1.4 \mathrm{ml} .100 \mathrm{~g}^{-1}\right) \mathrm{BV}$ during the control episode. In addition, the peritumoral region had a significantly higher BV

Table I Physiological parameters of tumour-bearing rats $(n=9)$, at each $\mathrm{FiO}_{2}$ level ${ }^{\mathrm{a}}$

\begin{tabular}{|c|c|c|c|c|c|c|}
\hline & Control & Normoxia & 0.15 & 0.12 & 0.10 & Reoxygenation \\
\hline $\mathrm{MABP}(\mathrm{mmHg})$ & $115 \pm 20$ & $120 \pm 15$ & $95 \pm 15$ & $90 \pm 20$ & $65 \pm 20^{b}$ & $125 \pm 25$ \\
\hline $\mathrm{PaO}_{2}(\mathrm{mmHg})$ & $144.6 \pm 16.2$ & $111.2 \pm 14.0^{b}$ & $56.5 \pm 5.8^{b}$ & $41.8 \pm 4.1^{b}$ & $35.4 \pm 2.8^{b}$ & $154.1 \pm 19.0$ \\
\hline $\mathrm{SaO}_{2}(\%)$ & $99.2 \pm 1.5$ & $94.4 \pm 5.7$ & $74.1 \pm 5.6^{b}$ & $55.2 \pm 5.4^{b}$ & $43.1 \pm 3.9^{b}$ & $98.9 \pm 2.4$ \\
\hline $\mathrm{PaCO}_{2}(\mathrm{mmHg})$ & $36.0 \pm 2.6$ & $35.9 \pm 4.8$ & $32.6 \pm 2.2$ & $31.1 \pm 2.5$ & $28.1 \pm 3.3^{b}$ & $34.0 \pm 2.6$ \\
\hline Pha & $7.34 \pm 0.03$ & $7.35 \pm 0.03$ & $7.39 \pm 0.02$ & $7.39 \pm 0.02$ & $7.37 \pm 0.07$ & $7.34 \pm 0.07$ \\
\hline $\mathrm{Hb}(\mathrm{g} / \mathrm{dl})$ & $13.6 \pm 0.9$ & $13.3 \pm 1.3$ & $13.3 \pm 0.2$ & $13.1 \pm 0.7$ & $12.5 \pm 0.9$ & $12.9 \pm 0.7$ \\
\hline
\end{tabular}

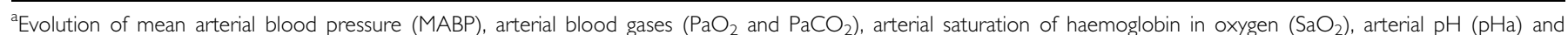
haemoglobin content $(\mathrm{Hb})$ at each episode of $\mathrm{FiO}_{2}$ (mean \pm s.d.). ${ }^{\mathrm{b}} \mathrm{P}<0.05$ compared to control value (Scheffé $\mathrm{F}$-test).

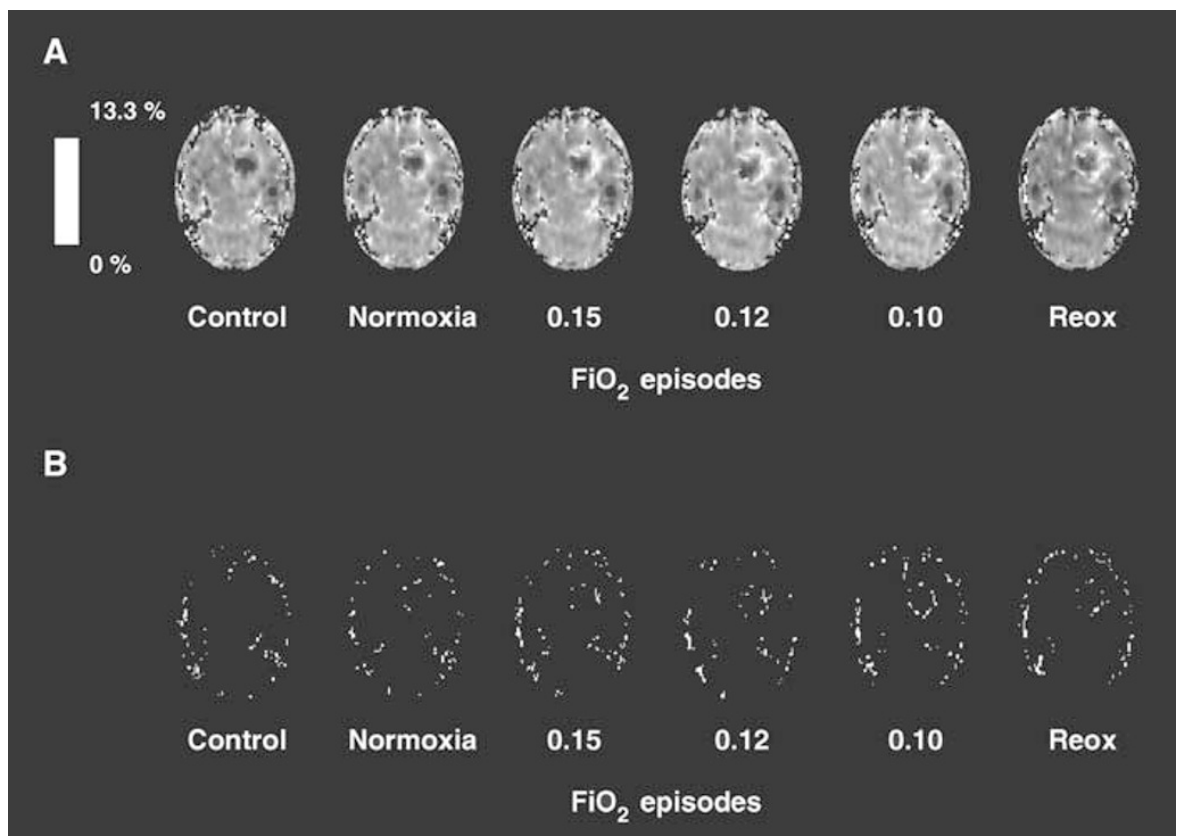

Figure 3 (A) Example of $\Delta R_{2}$ * maps for control episode ( $\mathrm{FiO}_{2}$ of 0.35$)$, normoxia episode $\left(\mathrm{FiO}_{2}\right.$ of 0.25$)$, hypoxia episodes $\left(\mathrm{FiO} \mathrm{O}_{2}\right.$ of $\left.0.15,0.12,0.10\right)$ and reoxygenation episode (Reox, $\mathrm{FiO}_{2}$ of 0.35 ). (B) Pixels discarded from $\mathrm{BV}$ measurement because of excessive $\Delta R_{2}{ }^{*}$ values. 


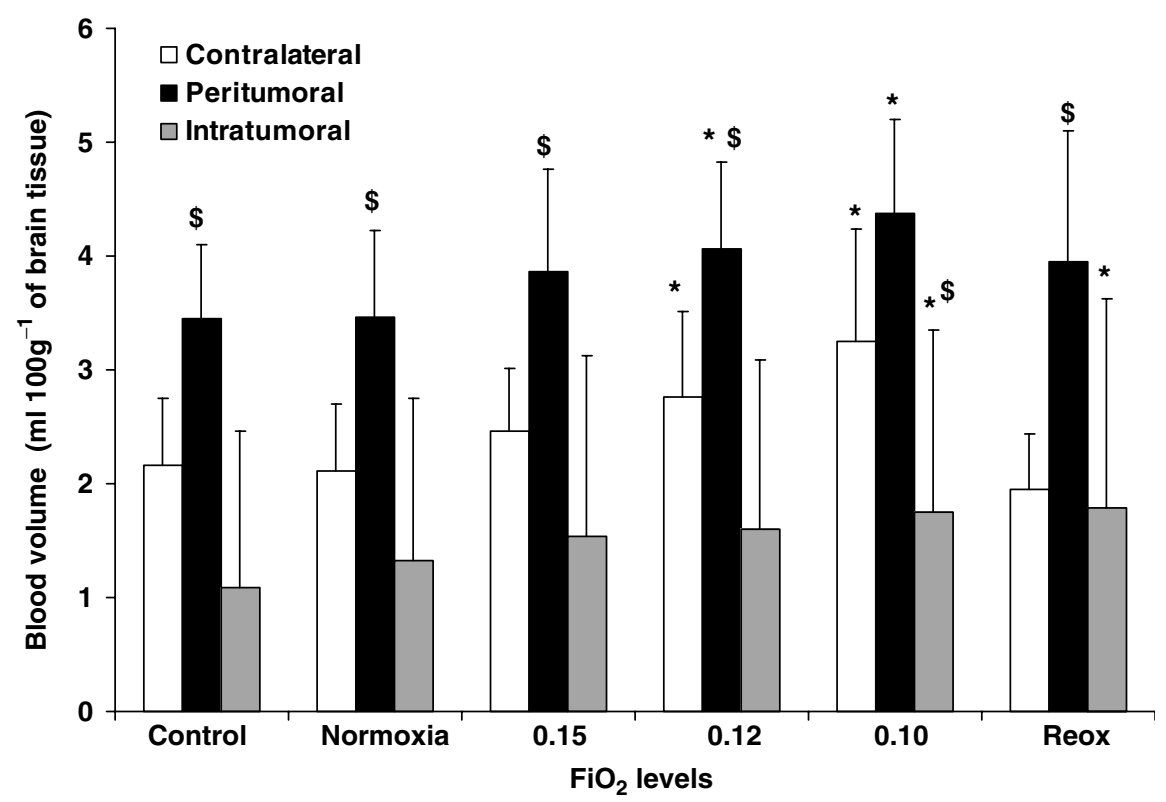

Figure 4 Evolution of blood volume (BV, in $\mathrm{ml} 100 \mathrm{~g}^{-1}$ of brain tissue) in peritumoral, intratumoral and contralateral regions during graded hypoxic hypoxia and reoxygenation $(n=9)$. Peritumoral and contralateral BV were reversibly increased during moderate hypoxia $\left(\mathrm{FiO}_{2} 0.12\right)$ while intratumoral BV was irreversibly increased during severe hypoxia $\left(\mathrm{FiO}_{2} \mathrm{O}\right.$. I $)$ ). $* \mathrm{P}<0.05$ between $\mathrm{FiO}_{2}$ compared to control value (Scheffé $\mathrm{F}$-test). Peritumoral region had a higher BV than contralateral and intratumoral regions. $\$ P<0.05$ between $\mathrm{ROI}$ compared to contralateral region at each $\mathrm{FiO}_{2}$ (Scheffé $F$-test).

than the contralateral region for each $\mathrm{FiO}_{2}$ episode, apart from $\mathrm{FiO}_{2}$ of 0.10 (Figure 4). The peritumoral and contralateral regions exhibited a significant graded increase in BV during hypoxia, with the greatest degree of hypoxia $\left(\mathrm{FiO}_{2}\right.$ of 0.10$)$ yielding to the largest $\mathrm{BV}$ increase. Contralateral BV increases were $28 \pm 14 \%$ of control value at $\mathrm{FiO}_{2}$ of 0.12 , and $49 \pm 22 \%$ at $\mathrm{FiO}_{2}$ of 0.10 . Peritumoral BV increases were $19 \pm 12 \%$ of the control value at $\mathrm{FiO}_{2}$ of 0.12 , and $28 \pm 17 \%$ at the $\mathrm{FiO}_{2}$ episode of 0.10 . These changes were reversed during reoxygenation, and the $\mathrm{BV}$ returned to control values in the contralateral and the peritumoral regions. It should be noted that no difference in $\mathrm{BV}$ changes was found between these two regions during the successive $\mathrm{FiO}_{2}$ episodes, including reoxygenation.

A large intervariability in absolute BV values and in BV changes was noted in the intratumoral region (Figure 4). Intratumoral BV significantly increased only at a $\mathrm{FiO}_{2}$ of $0.10(+186 \pm 253 \%$ of control values), although the absolute BV values were significantly lower than the contralateral BV at this level of hypoxia. Moreover, no evidence of return toward control values was found in this region during the reoxygenation.

Histological analysis confirmed that the C6 glioma developed at the expense of striatal tissue. The size of the brain tumour was not different between the rats. The peritumoral region in the MRI experiment corresponded to the limit between normal tissue and viable, non-necrotic, intratumoral tissue. Collagen and $\alpha$-SMA staining were used to qualitatively assess the number and morphology of all vessels and of the smooth muscle cells and pericytes characterising mature vessels respectively (Figure 5). In the peritumoral tissue, there were numerous vessels, mostly stained using $\alpha$-SMA. In the intratumoral region, few, large and tortuous vessels with no $\alpha$-SMA staining were depicted in the viable tumour tissue. There were no vessels in the necrotic areas.

\section{DISCUSSION}

Using the in vivo measurement of regional BV in a model of rat brain glioma, we found a comparable vascular response to graded hypoxic hypoxia of the peritumoral and contralateral regions. Combined with the histological study showing $\alpha$-SMA staining in the peritumoral region, these findings indicate that vessels in this region present intact vasoreactivity. Similar results using MRI and SMA staining were reported in a model of subcutaneous tumour exposed to hypercapnia (Abramovitch et al, 1999). This vascular reactivity could be taken advantage of to improve the delivery of antitumoral agent through the increase of local blood flow.

Some experimental points need to be addressed. First, despite epinephrine, the highest level of hypoxic hypoxia $\left(\mathrm{FiO}_{2}\right.$ of 0.10$)$ was associated with hypocapnia and with a decrease in $\mathrm{MABP}$, which a priori, might interfere with $\mathrm{BV}$ changes. However, as discussed elsewhere (Julien-Dolbec et al, 2002), the influence of these two parameters on BV changes is likely minor compared to that of severe hypoxia hypoxia, and should not invalid the comparison between regions of the response to hypoxia. Second, the relationship between $\Delta R_{2}{ }^{*}$ and BV postulates that the contrast agent must be confined within the vascular space. This particular point has been addressed by Dennie et al (1998), who showed that $\Delta R_{2}{ }^{*}$ did not change in rat brain tumour during $90 \mathrm{~min}$ following the administration of a contrast agent $\left(\right.$ MION) very similar to the present one (AMI-227/Sienerem ${ }^{\mathbb{R}}$ ). Since our experiment lasted about $75 \mathrm{~min}$, we considered that the contrast agent extravasation was negligible, regardless the status of the blood-brain barrier. The restoration of $\mathrm{BV}$ measurements to control values during the reoxygenation period suggests that extravasation does not occur in peritumoral region. Conversely, a leakage of contrast agent in tumoral region cannot be definitively ruled out.

The difference in the control values between the three brain regions can be due to a difference in their vessel density. Indeed, the large BV value found in the peritumoral region agrees with the high density of vessels reported by others (Deane and Lantos, 1981; Luthert and Lantos, 1985; Dennie et al, 1998; Peoc'h et al, 1999). Conversely, the low BV values found in the intratumoral region are consistent with the presence both of viable tumour tissue with few vessels and necrosis without vessels. A quantitative study was 


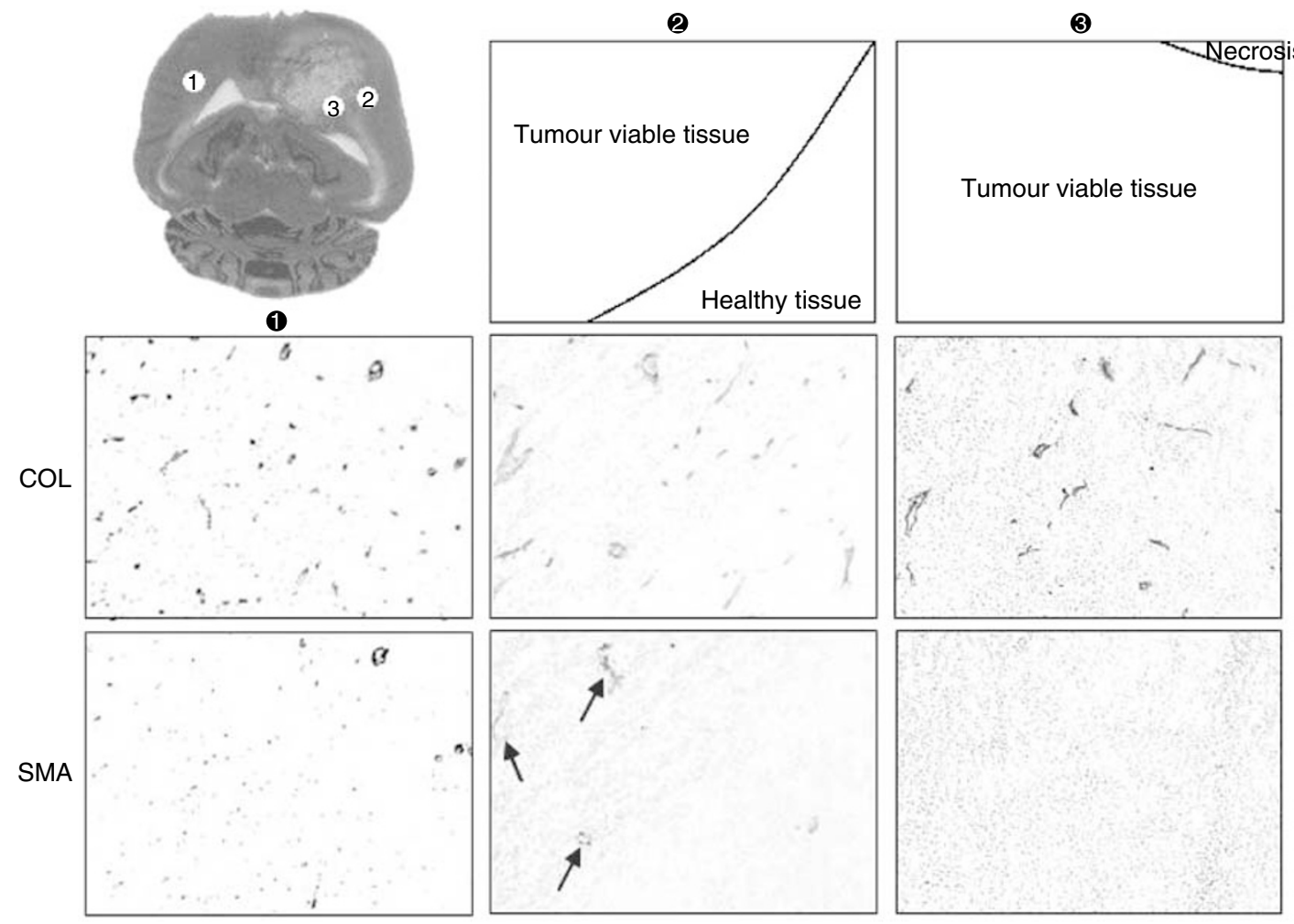

Figure 5 Immunohistochemistry detection in rat brain tumour in $\mathbf{1}$ contralateral, 2 peritumoral (at the border between normal and viable tumour tissues) and $\mathbf{3}$ intratumoral (viable tumour tissue near necrosis) regions. Histological staining was performed by HES. All vessels were stained using anticollagen antibody (COL) and mature vessels were stained using anti- $\alpha$ smooth muscle actin antibody (SMA). Some vessels in the peritumoral region exhibited both COL and SMA staining (indicated by arrows) suggesting reactive vessels to hypoxic hypoxia.

previously conducted to explore vessel density in the same model of rat brain tumour (Peoc'h et al, 1999), and our results are in agreement with this quantitative study. However, our control values of BV in the contralateral region $\left(2.2 \pm 0.6 \mathrm{ml} .100 \mathrm{~g}^{-1}\right)$ were notably smaller than those found in normal rat striatum using the same technique $\left(3.1 \pm 0.7 \mathrm{ml} .100 \mathrm{~g}^{-1}\right)$ (Julien-Dolbec et al, 2002). Similar findings concerning local cerebral blood flow were noted between normal rats and rats with brain glioma (Aizawa et al, 1990). These differences could be due to a tumour-related compression of surrounding tissues, particularly during the late stage of tumour growth.

It is established that hypoxic hypoxia is accompanied in the healthy brain by an increase in cerebral blood flow (Koehler et al, 1984). This increase is due to dilation of the cerebral arterioles (Kontos et al, 1978). Considering that pixels with high BV (i.e., BV $>13.3 \mathrm{ml} .100 \mathrm{~g}-1$ ) were excluded (see Materials and Methods section), the present changes in $\mathrm{BV}$ in the contralateral tissue should involve parenchymal arterioles and venules. The BV response to hypoxic hypoxia in this region $(+28 \pm 14 \%$ of control value at $\mathrm{FiO}_{2}$ of 0.12 ) was close to that reported in normal rats $(+38 \pm 25 \%)$ (Julien-Dolbec et al., 2002).

In brain tumour, there is a large heterogeneity in vessel morphology (number, size, connections). Previous studies (Abramovitch et al, 1999; Holash et al, 1999) indicated however that vessels located between normal and tumoral tissue have mostly $\alpha$-smooth muscle actin staining (as also shown in this study) and thus correspond to mature pre-existing vessels. Our results, showing comparable hypoxia-induced changes in $\mathrm{BV}$ in the peritumoral and the contralateral regions, are in line with these in vitro findings. Conversely, intratumoral tissue contains immature vessels and/or necrosis. The large, tortuous vessels with no $\alpha$-smooth muscle actin likely correspond to angiogenesis-induced neovessels (Deane and Lantos, 1981; Zama et al, 1991). In the present study, a significant change in intratumoral $\mathrm{BV}$ was found during severe hypoxic hypoxia $\left(\mathrm{FiO}_{2}\right.$ of 0.10$)$ only, with no return towards control values during reoxygenation. This can be explained by a possible extravasation of the contrast agent and/or a passive, hypoxicinduced vasodilation resulting from surrounding vasodilated tissue (Robinson et al, 1999). The large variability in BV values and BV changes in this region may be ascribed to a redistribution of the perfusion within the tumour (Dewhirst et al, 1989; Kuperman et al, 1995).

In conclusion, our study shows that the vascular response to a vasodilating stimulus such as hypoxic hypoxia can be measured in vivo in a model of rat brain glioma. Peritumoral vessels had a response to hypoxic hypoxia that was comparable to that from normal vessels. Susceptibility contrast MRI is an appropriate method for noninvasively demonstrating whether any particular vascular-modifying strategy results in the desired outcome in terms of tumour blood volume changes.

\section{ACKNOWLEDGEMENTS}

Cécile Julien received a $\mathrm{PhD}$ grant from Ligue Nationale Contre le Cancer. This study was supported by grants from the Association pour la Recherche sur le Cancer (ARC), the Comité de l'Isère de la Ligue contre le Cancer and the Programme Interdisciplinaire CNRS-INSERM-CEA 'Imagerie du petit animal'. We thank Guerbet (Aulnay-sous-Bois, France) for kindly providing the contrast agent AMI-227 (Sinerem ${ }^{\mathbb{R}}$ ). We also thank Patrick Canioni for having provided the C6 cells and Christoph Segebarth for his helpful comments on the manuscript. 


\section{REFERENCES}

Abramovitch R, Dafni H, Smouha E, Benjamin LE, Neeman M (1999) In vivo prediction of vascular susceptibility to vascular susceptibility endothelial growth factor withdrawal: magnetic resonance imaging of C6 rat glioma in nude mice. Cancer Res 59: 5012-5016

Aizawa S, Sako K, Yonemasu Y (1990) Measurement of cerebral blood flow, cerebral blood volume, and cerebral capillary permeability in gliomabearing rats. Neurol Med Chir (Tokyo) 30: 113-118

Benda P, Someda K, Messer J, Sweet WH (1971) Morphological and immunochemical studies of rat glial tumors and clonal strains propagated in culture. J Neurosurg 34: 310-323

Bereczki D, Wei L, Otsuka T, Acuff V, Pettigrew K, Patlak C, Fenstermacher J (1993) Hypoxia increases velocity of blood flow through parenchymal microvascular systems in rat brain. J Cereb Blood Flow Metab 13: $475-486$

Boxerman JL, Hamberg LM, Rosen BR, Weisskoff RM (1995) MR contrast due to intravascular magnetic susceptibility perturbations. Magn Reson Med 34: $555-566$

Damert A, Machein M, Breier G, Fujita MQ, Hanahan D, Risau W, Plate KH (1997) Up-regulation of vascular endothelial growth factor expression in a rat glioma is conferred by two distinct hypoxia-driven mechanisms. Cancer Res 57: $3860-3864$

Deane BR, Lantos PL (1981) The vasculature of experimental brain tumours. Part 1. A sequential light and electron microscope study of angiogenesis. J Neurol Sci 49: 55-66

Dennie J, Mandeville JB, Boxerman JL, Packard SD, Rosen BR, Weisskoff RM (1998) NMR imaging of changes in vascular morphology due to tumor angiogenesis. Magn Reson Med 40: 793-799

Dewhirst MW, Tso CY, Oliver R, Gustafson CS, Secomb TW, Gross JF (1989) Morphologic and hemodynamic comparison of tumor and healing normal tissue microvasculature. Int J Radiat Oncol Biol Phys 17: 91 - 99

Folkman J, Klagsbrun M (1987) Angiogenic factors. Science 235: $442-447$

Holash J, Maisonpierre PC, Compton D, Boland P, Alexander CR, Zagzag D, Yancopoulos GD, Wiegand SJ (1999) Vessel cooption, regression, and growth in tumors mediated by angiopoietins and VEGF. Science 284: $1994-1998$

Julien-Dolbec C, Tropres I, Montigon O, Reutenauer H, Ziegler A, Decorps M, Payen JF (2002) Regional response of cerebral blood volume to graded hypoxic hypoxia in rat brain. Br J Anaesth 89: 287-293

Koehler RC, Traystman RJ, Zeger S, Rogers MC, Jones Jr MD (1984) Comparison of cerebrovascular response to hypoxic and carbon monoxide hypoxia in newborn and adult sheep. J Cereb Blood Flow Metab 4: $115-122$
Kontos HA, Wei EP, Raper AJ, Rosenblum WI, Navari RM, Patterson Jr JL (1978) Role of tissue hypoxia in local regulation of cerebral microcirculation. Am J Physiol 234: H582-H591

Kuperman V, River JN, Lewis MZ, Lubich LM, Karczmar GS (1995) Changes in $T_{2}{ }^{*}$-weighted images during hyperoxia differentiate tumors from normal tissue. Magn Reson Med 33: 318-325

Luthert PJ, Lantos PL (1985) A morphometric study of the microvasculature of a rat glioma. Neuropathol Appl Neurobiol 11: 461-473

Mazurchuk R, Zhou R, Straubinger RM, Chau RI, Grossman Z (1999) Functional magnetic resonance (fMR) imaging of a rat brain tumor model: implications for evaluation of tumor microvasculature and therapeutic response. Magn Reson Imaging 17: 537-548

Payen JF, Vath A, Koenigsberg B, Bourlier V, Decorps M (1998) Regional cerebral plasma volume response to carbon dioxide using magnetic resonance imaging. Anesthesiology 88: 984-992

Peoc'h M, Le Duc G, Trayaud A, Farion R, Le Bas JF, Pasquier B, Remy C (1999) Quantification and distribution of neovascularization following microinjection of C6 glioma cells in rat brain. Anticancer Res 19: $3025-$ 3030

Robinson SP, Collingridge DR, Howe FA, Rodrigues LM, Chaplin DJ, Griffiths JR (1999) Tumour response to hypercapnia and hyperoxia monitored by FLOOD magnetic resonance imaging. NMR Biomed 12: 98- 106

Rofstad EK, Danielsen T (1999) Hypoxia-induced metastasis of human melanoma cells: involvement of vascular endothelial growth factormediated angiogenesis. Br J Cancer 80: 1697-1707

Shweiki D, Itin A, Soffer D, Keshet E (1992) Vascular endothelial growth factor induced by hypoxia may mediate hypoxia-initiated angiogenesis. Nature 359: $843-845$

Tropres I, Grimault S, Vaeth A, Grillon E, Julien C, Payen JF, Lamalle L, Decorps M (2001) Vessel size imaging. Magn Reson Med 45: $397-408$

Workman P, Twentyman P, Balkwill F, Balmain A, Chaplin D, Double J, Embleton J, Newell D, Raymond R, Stables J, Stephens T, Wallace J (1998) United Kingdom Co-ordinating Committee on Cancer Research (UKCCCR) Guidelines for the Welfare of Animals in Experimental Neoplasia (2nd edn.). Br J Cancer 77: 1 - 10

Yablonskiy DA, Haacke EM (1994) Theory of NMR signal behavior in magnetically inhomogeneous tissues: the static dephasing regime. Magn Reson Med 32: 749-763

Zama A, Tamura M, Inoue HK (1991) Three-dimensional observations on microvascular growth in rat glioma using a vascular casting method. J Cancer Res Clin Oncol 117: 396-402 